\title{
NFC Based Electronic Medical Record
}

\author{
https://doi.org/10.3991/ijim.v13i03.8047 \\ Noor Cholis Basjaruddin $\left({ }^{\varpi}\right)$, Edi Rakhman \\ Politeknik Negeri Bandung, Bandung, Indonesia \\ noorcholis@polban.ac.id \\ Kuspriyanto, Mikhael Bagus Renardi \\ Institut Teknologi Bandung, Bandung, Indonesia
}

\begin{abstract}
NFC technology allows off-line data transfer between mobile phones. In addition NFC also has a secure element section that allows to store data securely. Through special applications the data can be modified by the authorized party using an authentication system. In this study an electronic medical record was developed using NFC. The results of alpha and beta testing show that the application has good performance.
\end{abstract}

Keywords-NFC, Near Field Communication, Electronic Medical Record

\section{Introduction}

The development of medical record in the information age is electronic medical record (EMR). EMR is medical record that utilizes server as storage place, web as media for reading and updating data, and internet as communication media between server and web based application. The completeness and accuracy of medical record data on EMR can be better than conventional medical records. A well-built EMR meets at least some of the most important electronic data storage elements - privacy or confidentiality, integrity, authentication, access control and non-repudiation, but it is very difficult to meet availability. Medical record data that has been entered in EMR should be accessible whenever and wherever as needed. This availability requirement is difficult to meet due to its reliance on internet connection and the availability of server services where EMR is stored. Internet connections are often problematic so that medical record access can be disrupted especially in Indonesia internet connection is not evenly distributed. The availability of server services is also sometimes disrupted due to several reasons such as repair, maintenance, operating failure of server computers, and disrupted power supplies.

The retrieval and processing of data stored on the server can only be done online through the internet or intranet network. It is therefore necessary that technology allows the capture and processing of data off-line and under conditions that allow data stored on mobile devices to be sent to the server for wider purposes. Technology that can answer those needs is NFC. Through NFC data can be retrieved and processed off-line, but at the moment allowing such data can be sent to the server for wider purposes. In 
addition, NFC-based medical records also allow medical record data to be used by health care wherever independent of where the first medical record is made.

Electronic medical records research, among others, performed by [1], [2] and [3]. In [1] we investigated the benefits of EMR that facilitated administrative personnel in patient information retrieval, whereas at [2] and [3] it was suggested that EMR was beneficial for patients because it increased efiesiensi in the process of health care.

The development of smart card-based medical records was developed by [4], [5] and [6]. These three studies use RFID cards to store medical record data. The development of electronic medical records further exploits the NFC as performed by [3] and [7]. In addition to medical records the researchers also developed an NFC-based health care system such as [8] and [10].

\section{Literature Review}

\subsection{Medical record}

Medical Record is a file containing records and documents about the patient containing identity, examination, medication, other medical treatment on health care facilities for outpatient, hospitalized by both government and private [9]. The benefits of medical records include medicinal purposes, improvement of service quality, education and research, financing, health statistics, as well as legal, discipline, and ethical proofs.

The need for a practical, complete, and accurate medical record becomes an urgent need in today's healthcare services. The practicality of medical records, among others, can be seen from the media used in storing medical record data, the process of updating medical record data, and the process of reading medical records. Medical records are also required to contain complete information about the patient's medical history. Data on medical records is used as a reference of medical personnel in dealing with patients therefore this data must be accurate. Three properties of medical records are difficult to meet by conventional medical records by using paper as the medium. [10]

\subsection{Near Field Communication}

Smartphone technology continues to grow with the addition of various features that make this communication tool into multi-use. One feature that is currently embedded in the smart phone is Near Field Communication (NFC). This device allows the smart phone to communicate with other mobile devices without going over the cellular network at a distance of about $4 \mathrm{~cm}$. In addition via NFC smart phones can also read data stored in smart cards (NFC tags). Currently many smart phone devices are equipped with NFC. By 2018 about 1,907 million smart phones have been equipped with NFC [11].

Products with NFC capability will dramatically simplify how to interact with other NFC-enabled products because NFC offers fast connections in terms of secure exchange of information or payments. Standard communication between two devices 
that support NFC occurs when they are at a distance of 0 to $10 \mathrm{~cm}$ [12]. Simple or tactile movements can initiate NFC connections. Another advantage of NFC is compatible with bluetooth or Wi-Fi technology.

NFC and bluetooth are communication technology with short communication range that has been integrated with cellular phone. The main advantage of NFC over bluetooth is its very fast set-up time. If a bluetooth device needs to perform a manual process to identify another bluetooth device, the connection between two NFC devices can be done instantly $(<0.1$ seconds) [12]. Maximum NFC data transfer of $424 \mathrm{Kbps}$, lower than the bluetooth of $721 \mathrm{Kbps}$. NFC has a radius of communication that is closer than bluetooth that is less than $10 \mathrm{~cm}$. This provides a better level of security and makes NFC very suitable for crowded areas. Unlike bluetooth, NFC is compatible with existing RFID technology. Another difference with bluetooth is on the type of network used. NFC network type is point-to-point while bluetooth is point-to-multipoint.

NFC advantages over RFID include NFC can be used for two-way communication and installed on smart phones [13]. In addition, NFC is also equipped with a device capable of setting the secure element [14]. These advantages make NFC suitable for applications that require secure storage and exchange of data via smart phones such as e-payment applications [15] \& [16] or e-wallet [17], medical records [3], health services [18] \& [19], and airport services [20].

\section{$3 \quad$ Research Methodology}

Medical record activities based on Guidelines for Medical Record \& Procedure of Hospital 2006 include [9]:

- Acceptance of patient (recording of patient's social data)

- Recording of service data

- Data management

- Reporting

- Storage / Retrieval of data

Such activities shall be eligible for the implementation of privacy or confidentiality, integrity, authentication, access control, non-repudiation, and availability.

The development of NFC-based medical record that will be conducted covers all media recording activities as well as qualified in the implementation of such activities. The preferred approach in solving this problem is a system approach with high levels of security [21], accuracy, and reliability. Through this approach can be realized eligible system in the implementation of medical records.

This research begins with literature studies on medical records, electronic medical records, NFC, communication protocols, encryption, and applications in the android operating system environment. This literature study produces some information about aspects of medical record and NFC based system that can be used as base in determining the requirement and system specification. Based on the specifications and then designed the system with the beginning of the development of NFC-based medical record system 
architecture. Applications developed based on the architecture that has been developed with attention to the level of data security whether stored, read, or modified.

\section{$4 \quad$ Results and Analysis}

\subsection{Architecture}

The NFC-based EMR architecture can be seen in Fig [22]. The EMR application on the doctor's phone can be used to read and change the EMR content, while the EMR application on the patient can only be used for reading. When the patient first comes to the doctor and the doctor does not have the patient's EMR then the doctor needs to copy the EMR from the patient's phone by tap between the patient's phone and the doctor's phone. Upon medical examination of the patient then the doctor will renew the EMR and keep it. Patients will get the latest EMR from a doctor using NFC.

This architecture also allows one phone to be used to store multiple EMR from different people. Confidentiality is maintained with the use of autotentication in developed application.

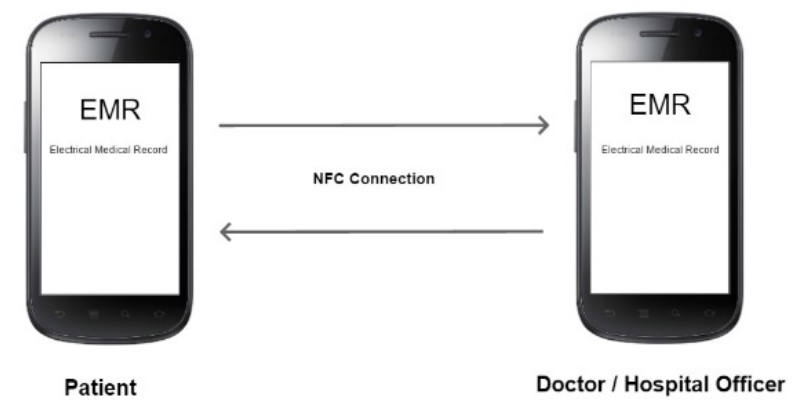

Fig. 1. NFC-Based EMR Architecture

\subsection{Use case}

The developed application consists of two parts: the first part is used by the doctor and the second part is used by the patient. Fig 2 shows the use case of the developed application. Patients are not entitled to add or change EMR, whereas doctors may add or change EMR.

Users of EMR application both a doctor and a patient must register on the application before using the EMR facility. After enrolling a doctor or patient can use the application after performing the autontication. Doctor use the application to create a new EMR or update an existing EMR. The latest EMR that has been made by the doctor is then sent to the patient via NFC by tap. If the patient visits another doctor, then the EMR stored in the patient's phone can be copied to the doctor's phone using NFC. The delivery process of EMR uses NFC so it does not depend on internet network. 


\subsection{Class diagram}

Class diagram of EMR application is presented in the form of model view control. Every strereotype in the class diagram represents a class in the application. The boundary/UI were created using XML, and the class control was created using Java. The database utilised to apply class entity was SqLite. Each boundary has a control to deal with processes. The control in the boundaries will attract another control to do a more specific process.

The login control is for examining whether an account exists. The account consists of two types, that is, patient's account and doctor's or hospital staff's account. Class UserLocal is utilised to store user's information that has logged in. Class account is used to save account's information, and class user is used to store information regarding users. Fig 3 shows the class diagram of application.

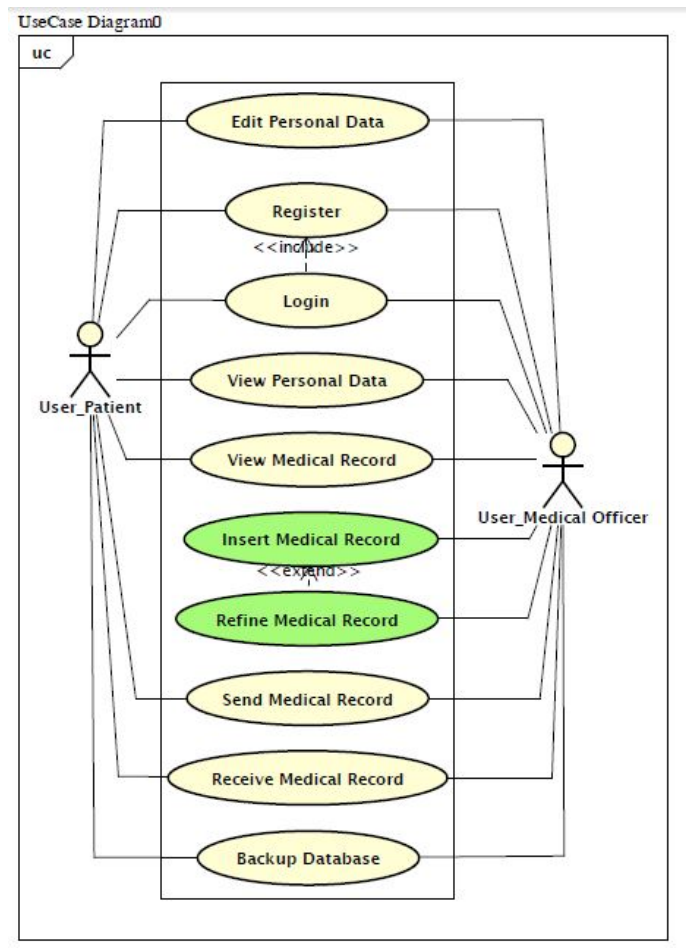

Fig. 2. Use case

\subsection{Alpha test}

Alpha test is used to test whether the entire application function can work properly or not. The test is done by using dummy data and the results can be seen in Table 1 The alpha test results show that the application can work in accordance with the requirements that has been set. 


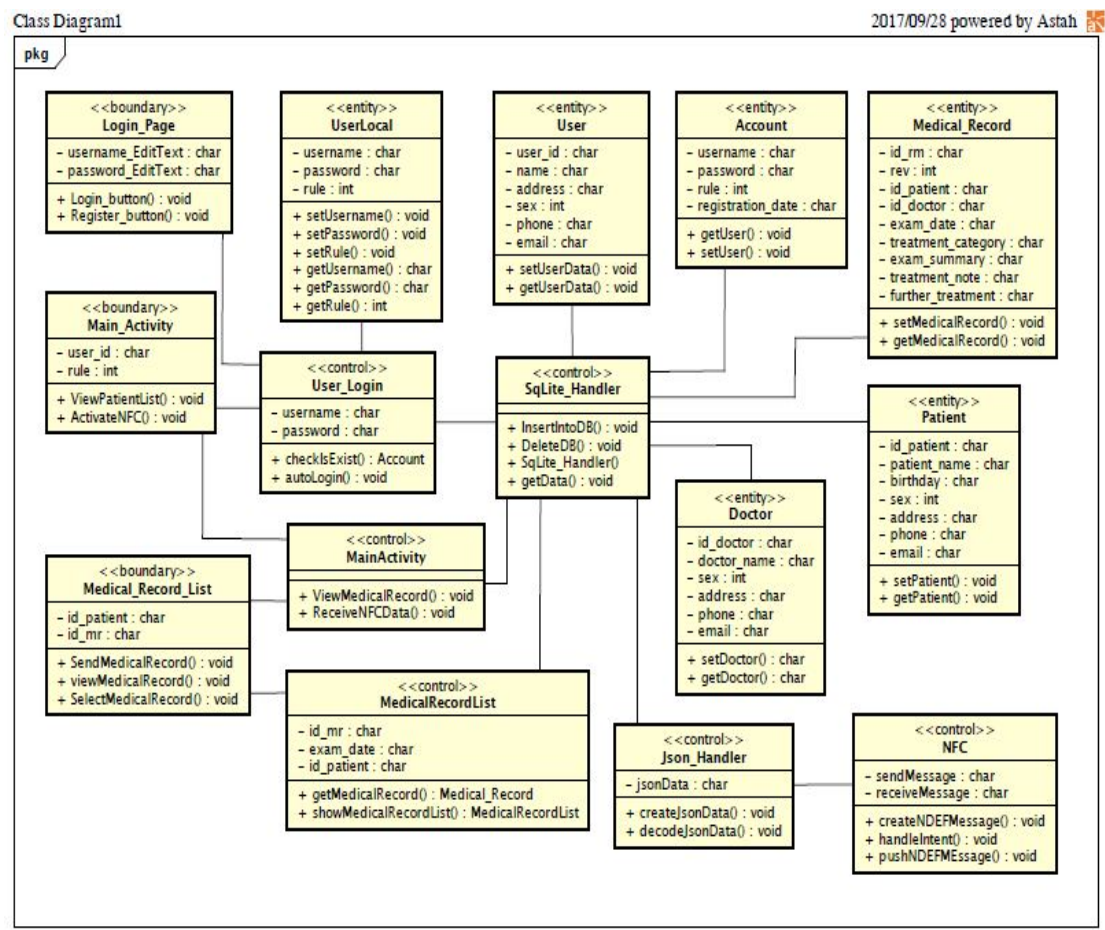

Fig. 3. Class diagram

\subsection{Beta test}

The next test to be performed is a beta test. In this test some doctors and patients will be involved. The beta test results will be a material improvement in application development. Through the beta test is expected to know how far the usability level of application by doctors and patients. The results of beta test in a hospital in Indonesia can be seen in Table 2 .

The MOS score calculation results show the average MOS score is 4.28. This shows that the developed application has good performance. The smallest MOS score is in question number 3. This indicates that the developed application still has a slight error. One example of an error that still occurs in the application is when sending of EMR data from the doctor to the patient or vice versa. If data sending is not successful the sender often presses the send button continuously so that the buffer becomes full. If the cellphone memory is small, it can cause freeze. In addition to errors, one of the weaknesses in NFC-based is that data is not stored on the server so online EMR usage cannot be done and this reduces the level of EMR data availability.

This research will be continued with the design and implementation of web-based EMR that will cover the shortage of NFC-based EMR. NFC and web based EMR will increase the availability of EMR data because it can be accessed on-line and off-line. The interesting thing about future research is the process of synchronizing content that is updated via NFC and the web. 
Table 1. Alpha test result

\begin{tabular}{|l|l|l|l|}
\hline \multicolumn{1}{|c|}{ Function } & \multicolumn{1}{|c|}{ Scenario } & \multicolumn{1}{c|}{ Actual Result } & Status (pass/fail) \\
\hline Patient Registration & $\begin{array}{l}\text { The researcher tried to enter } \\
\text { a new patient data into the } \\
\text { patient application }\end{array}$ & The new patient data added & pass \\
\hline Doctor Registration & $\begin{array}{l}\text { The researcher tried to enter } \\
\text { a new doctor data into the } \\
\text { doctor application }\end{array}$ & The new doctor data added & pass \\
\hline $\begin{array}{l}\text { Sending patient's data } \\
\text { to doctor's phone }\end{array}$ & $\begin{array}{l}\text { The researcher tried to sent a } \\
\text { patient data from patient's } \\
\text { phone to doctor's phone } \\
\text { using NFC }\end{array}$ & $\begin{array}{l}\text { Patient data sent to doctor's } \\
\text { phone }\end{array}$ & pass \\
\hline Insert New EMR & $\begin{array}{l}\text { An EMR insert to doctor's } \\
\text { phone }\end{array}$ & $\begin{array}{l}\text { An EMR added in doctor's } \\
\text { phone }\end{array}$ & pass \\
\hline Update EMR & $\begin{array}{l}\text { An EMR in doctor's phone is } \\
\text { updated }\end{array}$ & $\begin{array}{l}\text { An EMR in doctor's phone is } \\
\text { updated }\end{array}$ & pass \\
\hline $\begin{array}{l}\text { Sending an EMR data } \\
\text { from patient's phone } \\
\text { to doctor's phone }\end{array}$ & $\begin{array}{l}\text { Using two phones, the } \\
\text { researcher tried send a EMR } \\
\text { from patient's phone to } \\
\text { doctor's phone }\end{array}$ & An EMR sent to doctor's phone & pass \\
\hline $\begin{array}{l}\text { Sending an EMR data } \\
\text { from doctor's phone to } \\
\text { patient's phone }\end{array}$ & $\begin{array}{l}\text { Using two phones, the } \\
\text { researcher tried send a EMR } \\
\text { from doctor's phone to } \\
\text { patient's phone }\end{array}$ & An EMR sent to doctor's phone & pass \\
\hline
\end{tabular}

Table 2. Mean Opinion Score

\begin{tabular}{|c|l|c|c|c|c|c|c|}
\hline No & \multicolumn{1}{|c|}{ Question } & SA & A & LA & DA & SDA & MOS \\
\hline 1 & This EMR application is easy to install? & 8 & 7 & 0 & 0 & 0 & 4,53 \\
\hline 2 & Fast login access & 8 & 7 & 0 & 0 & 0 & 4,53 \\
\hline 3 & $\begin{array}{l}\text { There has never been an error in the EMR } \\
\text { application }\end{array}$ & 3 & 8 & 3 & 1 & 0 & 3,87 \\
\hline 4 & $\begin{array}{l}\text { Access time for each feature is fast and stable } \\
\text { The EMR application menus are easy to }\end{array}$ & 4 & 10 & 1 & 0 & 0 & 4,20 \\
\hline 5 & $\begin{array}{l}\text { Understand / familiar } \\
\text { Unerall, EMR applications are easy to operate }\end{array}$ & 6 & 9 & 0 & 0 & 0 & 4,40 \\
\hline 7 & $\begin{array}{l}\text { The filling of personal data and medical record } \\
\text { is easy }\end{array}$ & 5 & 10 & 0 & 0 & 0 & 4,33 \\
\hline 8 & $\begin{array}{l}\text { The data transfer process from HP doctors / } \\
\text { medical personnel to HP patients is easy to do }\end{array}$ & 5 & 8 & 2 & 0 & 0 & 4,20 \\
\hline 9 & $\begin{array}{l}\text { EMR application is useful for the process of } \\
\text { medical services for the community }\end{array}$ & 6 & 7 & 2 & 0 & 0 & 4,27 \\
\hline
\end{tabular}

*) $\mathrm{SA}=$ Strongly Agree, $\mathrm{A}=$ Agree, LA = Less Agree, $\mathrm{DA}=$ Disagree, $\mathrm{SDA}=$ Strongly Disagree

\section{Conclusion}

The NFC's ability to transfer data at close range safely without the need for an internet network allows it to be applied to various applications such as electronic medical records. Design and Implementation of NFC-based electronic medical records have been conducted in this study. From alpha testing can be concluded that the application can work in accordance with the requirements that have been set. The beta 
testing results show the average MOS score is 4.28. This score shows that the developed application has good performance.

\section{References}

[1] J. L. Schnipper, J. A. Linder, M. B. Palchuk, J. S. Einbinder, Q. Li, A. Postilnik and B. Middleton, "'Smart Forms" in an Electronic Medical Record: Documentation-based Clinical Decision Support to Improve Disease Management," J Am Med Inform Assoc, p. 513-523, 2008 . https://doi.org/10.1197/jamia.M2501

[2] L. Wilcox, D. Morris, D. Tan and J. Gatewood, "Using the Electronic Medical Record to Keep Hospital Patients Informed," Sciences New York, 2011.

[3] N. N. K. Razmi and A. B. Sangar, "The Use of NFC Technology to Record Medical Information in Order to Improve the Quality of Medical and Treatment Services," Modern Applied Science, 2016.

[4] C. X. Yu and Arthur, "Medical Smart Card System for Patient," Science, Technology, and Energy, 2009.

[5] M. M. Hansen, "Smart Card Technology and Healthcare Information: A Dynamic Duo," Computer Informatics, Nursing, pp. 254-257, 2008. https://doi.org/10.1097/ 01.NCN.0000304842.44584.42

[6] N. A. Latha, B. R. Murthy and U. Sunitha, "Smart Card Based Integrated Electronic Health Record System For Clinical Practice," (IJACSA) International Journal of Advanced Computer Science and Applications, 2012.

[7] A. Devendran and R. J. a. P. Sindhuja, "Electronic Medical Records Using NFC Technology," ARPN Journal of Engineering and Applied Sciences, 2015.

[8] A. Devendran and T. Bhuvaneswari, "Mobile Healthcare - Proposed NFC Architecture," IJSRP, 2012.

[9] Kemenkes, "Permenkes No. 749a Tahun 1989 tentang Rekam Medis," Kemenkes, 1989.

[10] J. Stausberg, D. Kochk and J. Ingenerf, "Comparing Paper-based with Electronic Patient Records: Lessons Learned during a Study on Diagnosis and Procedure Codes," Journal of the American Medical Informatics Association, vol. 10, 2003.

[11] statista.com, "statista.com," statista.com, 1 July 2014. [Online]. Available: https://www.statista.com/statistics/347315/nfc-enabled-phone-installed-base/.[Accessed 1 December 2017].

[12] T. D. Lazzari, "Architecture \& Development of NFC Applications," Smart University, 2009.

[13] P. R. Chopade, P. Deshmukh, K. Kamble and D. Nazarkar, "NFC Based Health Care System," IJISET - International Journal of Innovative Science, Engineering \& Technology, vol. 3, no. 3, March 2016.

[14] R. Vanderhoof, "Applying the NFC Secure Element in Mobile Identity Apps," 2012.

[15] E. Husni, Kuspriyanto and N. C. Basjaruddin, "Mobile Payment Protocol tag-to-tag Near Field Communication (NFC)," iJIM, vol. 6, no. 4, October 2012.

[16] E. Husni, Kuspriyanto, N. C. Basjaruddin, T. Purboyo, S. Purwantoro and H. Ubaya, "Near Field Communication (NFC) Protool Using Tag for Secure Mobile Payment," in Seminar on Intelligent Technology and Its Application (SITIA), Surabaya, 2012.

[17] E. Husni, Kuspriyanto, N. C. Basjaruddin, T. Purboyo, S. Purwantoro and H. Ubaya, "Efficient tag-to-tag Near Field Communication (NFC) Protocol for Secure Mobile Payment," in ICICI-BME, Bandung, 2011.

[18] C. L. Ventola, "Mobile Devices and Apps for Health Care Professionals: Uses and Benefits," $P \& T$, p. 356-364, 2014.

[19] A. S. M. Mosa, I. Yoo and L. Sheets, "A Systematic Review of Healthcare Applications for Smartphones," BMC Medical Informatics and Decision Making, 2012. https://doi.org/10.1186/1472-6947-12-67 
[20] M. B. Renardi, Kuspriyanto, N. C. Basjaruddin and A. Prafanto, "Baggage Claim in Airports Using Near Field Communication," Indonesian Journal of Electrical Engineering and Computer Science, vol. 7, no. 2, pp. 442-448, 2017. https://doi.org/10.1159 1/ijeecs.v7.i2.pp442-448

[21] M. B. Renardi, Kuspriyanto, N. C. Basjaruddin and E. Rakhman, "Securing Electronic Medial Record in Near Field Communication Using Advance Encryption Standart (AES)," Technology and Health Care, vol. 26, no. 2, pp. 357-362, 2018. https://doi.org/10.3 233/THC-171140

[22] N. C. Basjaruddin, E. Rakhman, Kuspriyanto and M. B. Renardi, "Developing Electronic Medical Record Based on NFC," in The 2017 International Conference on Computer Science and Artificial Intelligence (CSAI 2017), Jakarta, 2017.

\section{$7 \quad$ Authors}

Noor Cholis Basjaruddin was born on June,1967, Indonesia. He received the B.S., M.S., and Ph.D. degrees in Electrical Engineering from Bandung Institut of Technology at Bandung, Indonesia in April 1992, October 2002, and October 2015 respectively. He is head of Mechatronics Laboratory of Electrical Departement and head of Diploma IV Electronic Engineering Study Program, Bandung State Polytechnic. Basjaruddin, Ph.D research interests are in Mechatronics, Advanced Driver Assistance Systems (ADASs), Intelligent Transportation System (ITS), Fault Tolerance System Design, Humman Error, Dependable System, and NFC and IoT based applications.

Edi Rakhman was born on January, 1965, Indonesia. He received the B.S. degree in Electrical Engineering from Bandung Institut of Technology in 1993, and the M.S. degree in Electrical Engineering from Gajah Mada University (UGM) in 2011. He is head of Diploma III Electronic Engineering Study Program, Bandung State Polytechnic. Ir. Edi Rakhman, M.Eng research interests are in industrial control system, computer network system, and mechatronic system.

Kuspriyanto was born on January, 1950, Indonesia. He received the B.S. degree in Electrical Engineering from Bandung Institut of Technology in 1974, and the M.S. and Ph.D. degrees in Automatic System from University of Science and Technology Lille (USTL) at France in 1979 and 1981, respectively. He was the vice chairman of Indonesian Control Systems Society (ICSS) (during 1996-1998). He is chairman of Computer Enginering Research Group School of Electrical Engineering and Informatics, Bandung Institute of Technology (2006-2010, 2014-now). Prof. Dr. Kuspriyanto research interests are in Real Time System, Fault Tolerance System Design, Dependable System, and Computer Architecture.

Mikhael Bagus Renardi was born on September 1991, Indonesia. He received the B.S. degree in Computer Science/Informatics from Diponegoro University in 2014 and the M.S. degree in Electrical Engineering of School of Electrical Engineering and Informatics from Bandung Institute of Technology at Bandung, Indonesia in 2017. Mikhael Bagus Renardi, S.Kom., M.T. research interests are particularly in Integrated Information System, Software Engineering, and Mobile Application Development.

Article submitted 2017-12-01. Resubmitted 2018-12-20. Final acceptance 2018-12-21. Final version published as submitted by the authors. 